\title{
Epilepsy and violence: case series concerning physical trauma in children of persons with epilepsy
}

This article was published in the following Dove Press journal:

Neuropsychiatric Disease and Treatment

14 November 2014

Number of times this article has been viewed

\author{
Helena Gauffin ${ }^{1,2}$ \\ Anne-Marie Landtblom ${ }^{1-4}$ \\ 'Department of Neurology, \\ Linköping University, Linköping, \\ Sweden; ${ }^{2}$ Department of Clinical and \\ Experimental Medicine, Linköping \\ University, Linköping, Sweden; \\ ${ }^{3}$ Neurology Unit, Department of \\ Medical Specialist, General Hospital, \\ Department of Medicine and Health \\ Sciences, IMM, County Council, \\ Linköping University, Motala, Sweden; \\ ${ }^{4}$ Department of Neuroscience, \\ Uppsala University, Uppsala, Sweden
}

Correspondence: Helena Gauffin Neurologmottagningen,

Universitetssjukhuset i Linköping,

S-58I85 Linköping, Sweden

Email helena.gauffin@lio.se

\begin{abstract}
Historically, epilepsy has been associated with violence, but more recent studies have emphasized genetic and psychosocial factors as more important. The case series presented here aim to highlight the difficult situation the affected children are in. We report on three cases when children have been traumatized and, in one case, even been killed by their parent who was diagnosed with epilepsy. In the first case, we describe a woman with juvenile myoclonic epilepsy who was sentenced to forensic psychiatry care for killing her child. She lived under difficult psychosocial circumstances and a suicide attempt contributed to what happened. The second case describes a man with post-traumatic seizures who was sentenced for child abuse. Ictal or postictal violence was considered in these two cases but a causal link between the violence and epilepsy has not been established. In the third case, we describe a woman with focal epilepsy and psychogenic non-epileptic seizures (PNESs). Her child was hurt and frightened in relation to violent seizures, which were regarded as PNESs. This case series demonstrates that children of parents with epilepsy can be in a vulnerable situation. No causality has been established between the seizures and these events, so consequently other factors such as psychosocial stress, low cognitive function, and a suicide attempt must also be considered as important. When a child is hurt by a parent with epilepsy the patient must be closely examined to determine the role of the seizures. Children can also be affected by PNESs. It is essential to notice especially those children of parents with epilepsy who live under difficult psychosocial circumstances and offer extra support when necessary.
\end{abstract}

Keywords: homicide, epilepsy, child abuse, children, psychosocial, crime, law

\section{Introduction}

Epilepsy has historically been associated with violence, and this has aggravated the psychosocial stigma of the condition. Epilepsy and violence can be connected for different reasons. ${ }^{1}$ Firstly, violent behavior can be associated with underlying brain dysfunction, postictal confusion or psychosis, and sometimes with ictal aggressions. It may occur during seizures (ictal violence), between them (inter-ictal violence), or directly after them (postictal violence). Epilepsy is also associated with an increased prevalence of mental-health disorder compared with the general population, ${ }^{2}$ and people with epilepsy (PWE) more often have general anxiety disorder, depression, autism spectrum disorder, and suicidal intention. ${ }^{3}$ Psychosis is also more frequent in PWE, ${ }^{4}$ which can increase the risk of violence. Even though violence has been associated with epilepsy, the connection is most probably overemphasized. ${ }^{5}$ However, there is one group of special interest when it comes to preventing violence with a harmful 
effect, and that is children of PWE. We have an interest in these matters as three epilepsy patients at our clinics have injured their own children.

As a literature search revealed that little has been published on this subject, this article aims to focus on situations in which these children can be at risk, by relating other relevant case reports of violence having occurred. In a qualitative study published earlier by our group, ${ }^{6}$ we give a more detailed description of the psychosocial stress from which PWE may suffer in relation to the reduced capability to look after their children that some of them report. Many of the participants in the focus group interviews we performed were worried about how their epilepsy affected their children's situation. They were concerned about the psychosocial stress and increased responsibility the children faced, but some also expressed that there could be physical risks for their children - for example, the risk of dropping a child if a seizure occurred. Not much is known about the situation for children of persons with chronic disease. One may suspect that these children could be at risk of developing psychosocial or psychological problems, or even physical symptoms. A literature search revealed only a few reports of the situation for children of persons with epilepsy, ${ }^{7,8}$ but these articles describe the children's psychosocial situation rather than focusing on the physical risks they possibly face. One author, for example, describes that the epilepsy of one parent changes the family roles, and fear and anxiety can disrupt the family equilibrium. ${ }^{7}$

\section{Methods}

Three clinical case reports from our clinics are presented here, which describe children who have been injured by a parent with epilepsy. We also did a literature and data search for cases when children have been hurt by a parent with epilepsy.

\section{Ethics}

The study was performed according to the Declaration of Helsinki. The participants gave oral and written informed consent.

\section{Cases \\ Case I}

Our first case describes a 30-year-old woman who was sentenced to forensic custody for the death of her young child. This patient had juvenile myoclonic epilepsy, for which she has received treatment with antiepileptic drugs (AEDs) since she was 5 years old. Electroencephalographs (EEGs) showed a great number of poly spikes and wave complexes in episodes with generalized distribution. Her mother, one sister, and one brother all had epilepsy, probably all of generalized classification. She lived under difficult conditions as a child and on two occasions she tried to commit suicide, because her own attempts to be transferred to a foster home were not successful.

In the time period before the killing of the child, the patient had myoclonic jerks two to three times every month that sometimes lasted as long as 30 minutes. She also had generalized tonic-clonic seizures in some periods - as many as three to four times per month, but mostly more infrequently. She was taking a combination of two AEDs, carbamazepine and clonazepam, which were later combined with levetiracetam due to unsatisfactory seizure control. This period of her life was stressful because her fiancé, the father of her son, wanted a separation and had left her. There were repeated conflicts between the two, and she felt that the man did not help her enough in caring for their 2-year-old son. The patient wanted the relationship to continue, but suspected that her fiancé had met another woman, and she felt very jealous and upset. She later explained that she suffered from depression during this time and that she had also applied for support from the social authorities, but this was denied.

This woman was accused of the manslaughter of her child. The day the child was killed she made a suicide attempt, but she denies she had any plans to kill her son. To commit suicide she took AEDs, paracetamol, and asthma medication, and cut her wrists. After this she cannot remember what happened until, upon awaking, she saw her 2-year-old son, dead from suffocation, beside her on the bed and called the police, realizing that it must have been she herself who had caused his death. She is convinced that she had repeated seizures in association with the intoxication caused by the overdose and when waking up she felt myoclonic jerks.

Later, at clinical visits due to her epilepsy, she could never explain how the killing had actually happened, but said she suffered from intense despair and hatred toward her former fiancé because of his refusal to help with their son and because of the risk of losing the custody of the child to him. Furthermore, as she put it, "Maybe I subconsciously had some vague thoughts of harming my former fiancé." She still denies that she planned to kill or harm her child, but in retrospect she hints that the death of the child could be revenge on her former fiancé. Obviously, this has some similarities to the Medea situation in the famous tragedy of the same name. She was not sentenced to jail, but was referred to a clinic for forensic psychiatry where she underwent regular 
psychotherapy. Neuropsychological examination revealed mild cognitive dysfunction, autism spectrum traits, and a maladaptive stress reaction. Previous experiences, such as sexual assault and abuse, were brought to light, and she later expressed that she is now in better psychological shape than ever. She deeply regrets what she did and she believes that the epilepsy condition had a great impact on the course of the event.

\section{Case 2}

This case concerns a male patient who suffered from posttraumatic epilepsy with focal seizures, with and without affected consciousness. He got epilepsy after a traffic accident with head trauma to the left temporal area. There was nothing particular about his remote anamnesis; only a description by his mother that there had been another accident when he was a year old, in which he was thrown out of a car window. He had focal seizures, starting with clonic seizures in the right arm, sometimes continuing with impaired consciousness and thereafter tonic-clonic generalized seizures. His computed tomography (CT) scan and EEGs were normal. The posttraumatic epilepsy was severe with seizures every month, and seizure control had never been satisfactory before the trauma to the child. He was treated with carbamazepine and lamotrigine. He also suffered from chronic headaches after the head trauma, and temporarily used high doses of analgesics including codeine.

The patient was married, and his first child was born when he was in his mid-20s. When the baby girl was just a few months old she was examined more closely after contact with primary health care, because she was crying excessively and seemed to be suffering from some kind of pain. The investigation revealed that the baby had been exposed to repeated and severe trauma, resulting in $17 \mathrm{frac}-$ tures of different ages, visible by X-ray. On one occasion, the baby also demonstrated a vulnus at the oral superior labial frenulum, a typical sign of abuse. The pediatrician declared a high possibility of child abuse, and the patient was primarily suspected of having committed this offence. A neuropsychological examination did not reveal any gross abnormalities. The patient had regular clinical contact with his neurologist during this time, and repeatedly stated that he had no clear memory of having traumatized his baby. He tried to remember details from the time period when the traumas were believed to have occurred. This was a period of stress for the parents, as the mother was exhausted after the delivery. The patient declared that he tried to support her by caring for the newborn at night, for example, by changing diapers or otherwise tending to the baby, in order to let the mother sleep. During some periods he got little sleep and woke up often. He could not remember any accident having happened to the baby when she was under his care, but could not totally dismiss the possibility that he may have had disturbances of attention due to focal seizures with impaired consciousness.

After several encounters during which he was encouraged to remember anything out of the ordinary when tending to his daughter at night, he finally declared that he had a vague recollection, a "flashback" as he called it, of suddenly regaining consciousness as the baby cried. He described seeing blood in the baby's mouth. Eventually, many events were scrutinized to rule out the possibility that someone or something else might have been responsible, for example, whether the family dog could have harmed the child, that some stranger could have come into the home, or that one of the child's grandparents could have hurt her. The patient was constantly anxious that the mother of the child would be accused of the abuse, and eventually declared that he was willing to take the blame for it; firstly, to keep any suspicion from falling on the mother, and secondly, because "Who other than me myself could have hurt the baby?"

He was sentenced to 3 years in prison, but was released early for good behavior. His neurologist declared in court that the possibility of postictal confusion could not be ruled out, although the direct causation of the abuse could not be specified. Another expert on epilepsy who had also encountered the patient on several occasions had another point of view, as did the pediatrician, both of whom claimed that this was an ordinary case of severe child abuse and that the patient's epilepsy should not be taken into account in the judgment or sentencing. The latter neurologist even underlined that such acts of abuse would be impossible to perform during a focal seizure with impaired consciousness, or in the postictal phase.

Shortly before the patient was imprisoned he and the child's mother separated, but they eventually got back together and during his imprisonment even had another child. Shortly after being released from prison the patient and his partner separated again, "as friends", and he is now married to another woman. He has regular contact with his children from the previous relationship, is working, and has no further criminal record to our knowledge. He has been seizure-free for several years, and is convinced that the trauma to his child occurred in relation to a seizure. He is therefore eager to continue using AEDs on a regular basis. 


\section{Case 3}

The woman in this case has suffered from epilepsy since she was a teenager, although it was not until later that she was correctly diagnosed. She had previously been regarded as having psychological problems, and was examined at a psychiatric clinic. When she was in her 30s she finally received the diagnosis of epilepsy with focal seizures of unknown origin, with occasional generalizations. The investigation at this time showed no epileptic foci on magnetic resonance imaging (MRI), but EEGs were pathological with right-side abnormality and with plenty of 3-4 Hz epileptiform activity localized to the right temporal lobe.

The situation worsened, with frequent seizures, and grew even worse when she had a traffic accident and suffered a whiplash injury. At this time, she described different kinds of seizures, and the semiology described varied and included seizures with and without impaired consciousness. They started with a strange feeling and she then had an adversive movement of the neck continuing with clonic jerks in the neck which later spread to the arms which rotated in a fast and lively manner. This kind of seizure occurred several times every week - sometimes several times each day. Generalized tonic-clonic seizures with apnea were also described but less often. When waking up she used to have muscle pain and was very tired. At this time a videoEEG-telemetry analysis was performed primarily because the neurologist suspected focal seizures with a frontal component, but the seizures registered (the first one as already described) were regarded as psychogenic non-epileptic seizures with hyperventilation.

When her husband was working, the patient often took care of their two small children alone, which was also during a period of frequent seizures. Once when she was alone with the children the patient had a seizure and became aggressive, rotating her arms, and involuntarily hit one child, who was not actually hurt, but frightened. The husband confirmed that the child had been hit in association with the kind of seizures that were registered and regarded as psychogenic non-epileptic seizures (PNESs). This happened again, and the husband sought care at the epilepsy policlinic in order to get support, for example, a home aid from the social authorities. However, the municipality did not consider this necessary. The situation deteriorated, with frequent seizures occurring, and the husband often had to leave work in order to check on the situation at home. Increased pressure on the social authorities from the patient's family and the responsible neurologist did not help.

Finally, the patient's husband ceased demanding help. In the Swedish media he heard of a Vietnamese immigrant couple whose newborn had been away from them and placed in a foster home because of the mother's chronic and severe epilepsy. This was later re-analyzed, the decision changed, and the baby was returned to the parents. The husband of the patient discussed here, however, feared that his children could be taken from their home because of their mother's epilepsy, so from this point on he did not ask for help from the social authorities. Recently, he has considered quitting his job and remaining unemployed in order to be able to look after his family.

\section{Discussion}

A recent and, obviously, very important article demonstrates that the risk of violence in PWE is not increased compared with in their healthy siblings, indicating that violent behavior is rather associated with a common environment or even genetic background. ${ }^{9}$ In addition, the same study reveals that the risk of violence is significantly connected to a history of head trauma. Herein, we have presented three cases in which children were hurt or even killed by a parent with epilepsy. These parents, in different ways, all lived under psychosocially difficult circumstances, which contributed to the events.

Case 1 patient suffered from depression, and was also intoxicated because of the suicide attempt when she committed the offence. The psychosocial situation was hard and many other factors aside from epilepsy contributed to what happened. It was, however, not ruled out that the child was killed in relation to a seizure. The intoxication due to the suicide attempt could have changed the postictal behavior and caused the attack on the child. One possible explanation is that that the patient's feelings of hatred and wish for revenge toward her former fiancé could not be controlled in the postictal state.

Case 2 is the only report out of the three that concerns trauma-induced epilepsy. It is not possible to determine if this man hurt his child because of ictal or postictal aggression, since there were no witnesses. Ictal aggressions are usually resistive and have no specific purpose, and ictal automatic behavior is believed to be a rare explanation for violence in epilepsy. ${ }^{10,11}$ Some authors claim ${ }^{12}$ that ictal violence can be directed and interactive, while others report that it is stereotyped and not targeted to a specific aim. ${ }^{13,14}$ Postictal confusion is a more frequent problem and may result in violence, but in most cases the aggressions are resistive in these cases as well. However, postictal aggressions may also be uniquely stereotyped for each patient and occur repeatedly in the same manner after a seizure. ${ }^{15}$

Other factors of interest are low performance in cognitive tests or being a single parent. The child described in Case 2 
had many fractures of different ages and therefore this case is less likely to have any relation to seizures. It is not likely that seizures will happen in the same situation and cause similar harm to a child several times without being noticed. One scenario discussed was the baby falling from the baby dressing table repeatedly if the patient had night-time seizures. However, this was regarded as less likely by the experts and the patient could not remember lifting the child from the floor.

Abuse is the most probable explanation for the offence, but since there are no witnesses and no explanation from the patient, we do not know this for sure.

Interestingly, the Case 3 patient probably had focal seizures of unknown origin which spread to generalization, but she also had PNESs, which caused her to hit her children, so obviously, even if the seizures are PNESs, there can be a risk to the child. This woman had low function on cognitive tests and suffered from other conditions that contributed to her hardship. The PNESs often started with pain in her neck, associated with the whiplash injury. The children were never really injured, but they were frightened and the family claimed that they needed increased social support.

We cannot dismiss the possibility that the three parents presented in this article developed violent behavior toward their children during seizures; this is possible, since none of them is able to remember or express what happened. The man in Case 2 is convinced that the incident happened during a seizure, and has not experienced anything similar since he became seizure-free. However, ictal violence is believed to be very rare, and some authors nearly exclude the possibility that a crime could be committed during a seizure. ${ }^{13}$ When ictal violence occurs, it is explained as resistive violence as a result of physical restraint at the end of a seizure. ${ }^{16}$
It has been proposed, but not confirmed, that frontal-lobe seizures may be associated with ictal violence in a small number of cases. Examining case series based on criminal reports from England and Wales has also confirmed that it is exceptional for epileptic seizures to result in criminal acts, and that most such events have occurred in the postictal phase. ${ }^{17}$ Gerard et al have published six cases of postictal aggression that were all directed and targeted at a specific individual or object ${ }^{15}$ Pandya et al, who recently published a literature search on epilepsy and homicide, ${ }^{5}$ describe some common characteristics of these crimes. The offender is most often a man of young age with a long history of epilepsy and lower than average intelligence, and the aggression is most often postictal and related to alcohol abuse. They also state that the link between epilepsy and aggression has been disproportionally emphasized.

We have found no studies examining the risk of accidents in children of parents with epilepsy. In an examination of children in England drowning or nearly drowning in the bathtub, four of 44 cases were related to epilepsy, but in every one of those cases it was the child rather than the parent who had epilepsy. ${ }^{18}$ A literature and data search for case reports of children hurt by their parent with epilepsy revealed only three published cases, indicating that such tragic events are rare (Table 1).

The first case from the literature search describes a mother who had been seizure-free for a long time and who had a generalized seizure when bathing her infant. ${ }^{1}$ This case clearly describes a non-deliberate accident. The second and third cases describe persons with epilepsy but also psychiatric illness and the crimes described were not regarded as related to seizures. ${ }^{1,19}$ Contrary to these two case reports, which describe patients with serious psychiatric illness, the patients

Table I Previous case reports concerning children injured by their parent with epilepsy

\begin{tabular}{|c|c|c|c|}
\hline Study & Person & Event & Later consequence(s) \\
\hline $\begin{array}{l}\text { Marsh and } \\
\text { Krauss (2000)' }\end{array}$ & $\begin{array}{l}\text { 29-year-old woman with } \\
\text { generalized epilepsy }\end{array}$ & $\begin{array}{l}\text { Had a generalized seizure when bathing her infant } \\
\text { in a bathtub. When waking up found her infant } \\
\text { dead. This woman was not prosecuted }\end{array}$ & $\begin{array}{l}\text { This woman was } \\
\text { not prosecuted }\end{array}$ \\
\hline $\begin{array}{l}\text { Marsh and } \\
\text { Krauss (2000)' }\end{array}$ & $\begin{array}{l}\text { 19-year-old woman with focal } \\
\text { seizures with impaired } \\
\text { consciousness }\end{array}$ & $\begin{array}{l}\text { History of confused behavior during seizures. } \\
\text { Family members found her confused without her } \\
\text { infant, who later was found dead in the microwave } \\
\text { oven. Complex behavior which was not regarded } \\
\text { as seizure but rather as psychosis or depression }\end{array}$ & $\begin{array}{l}\text { Complex behavior which } \\
\text { was not regarded as seizure } \\
\text { but rather as psychosis or } \\
\text { depression }\end{array}$ \\
\hline Treiman (1999) ${ }^{19}$ & $\begin{array}{l}37-y e a r-o l d ~ m a n \text { with focal seizures } \\
\text { with impaired consciousness and } \\
\text { PNESs. Cavernous angioma in the } \\
\text { right temporal lobe }\end{array}$ & $\begin{array}{l}\text { Became frequently violent and now and then } \\
\text { grabbed his daughter hard and frightened her }\end{array}$ & $\begin{array}{l}\text { Later murdered a young } \\
\text { girl and was sentenced to } \\
\text { treatment at a psychiatric } \\
\text { facility for the criminally } \\
\text { insane }\end{array}$ \\
\hline
\end{tabular}

Abbreviation: PNESs, psychogenic non-epileptic seizures. 
in the present report had milder psychiatric difficulties, but none of them suffered from psychosis or delusions.

Treiman has published guidelines for testimony regarding the possible relation of a violent event and a seizure. ${ }^{19} \mathrm{He}$ advises that the diagnosis should be established by an epileptologist and that the violent act must be characteristic of the patient's habitual seizures. Both the presence of aggressions and of epileptic automatism should be recorded on videoEEG-telemetry. Only one of the patients described in this article had a video-EEG-telemetry and in that case it gave relevant information about what happened.

There is a need for more support for PWE with children than is offered today, especially if they are single parents or if their spouse cannot support the identified needs. PWE with children seem to suffer from double trauma: firstly, the risk of having seizures and the constant fear this can create; and secondly, worries about generating psychological and physical problems for their children. We also suspect that there may be such risks for some children of persons with epilepsy that the parents do not recognize themselves.

Two of the patients described herein had hyposomnia at the time of the events, which may have been a contributing factor. The patients were also alone with their children when the incidents occurred. If a patient has recurrent seizures, it is not appropriate that they be left alone with their child. In Sweden, it is sometimes possible for the parent with epilepsy and frequent seizures to be sick-listed from the duty of caring for the child, and for the other parent to receive compensation for parental leave. Other solutions can include the social authorities sending a carer to the home to assist the family with the child.

Parents can also fear that their child will be taken into custody if they expose the possible risks to the social authorities. This was evident in Case 3, in which the husband was considering quitting his job to take care of his children instead of asking the social authorities for help. It is essential that parents with epilepsy have the opportunity to get support in their homes if necessary, so they do not have to conceal their worries about the child's safety. The help offered to PWE for supporting their children must be designed in a way that the patient need not unnecessarily fear an intervention; instead, the action taken should be beneficial to the whole family.

Our article stresses the physical risk to children of PWE, and the need to develop support for these families. The cognitive profile may be a factor that should be investigated in this situation - low performance may be a risk factor but further research is needed. Other potential risk factors include being a single parent with epilepsy, living under difficult psychosocial circumstances, and using alcohol and drugs. A previous study has shown that self-esteem among young adults with epilepsy decreases when they have passed adolescence and begin facing the different obstacles of adult life, ${ }^{20}$ such as getting a job and raising a child. Therefore, it is essential that members of this group get support from society, so that they can create a good, safe environment for their child.

\section{Conclusion}

We present three cases in which children have been hurt by a parent with diagnosed epilepsy. In Cases 1 and 2 we find it less likely, but not impossible, that the children were hurt because of seizures, and no causality has been established. Non-resistive violence as well as repetitive stereotyped violence are very rare in association with a seizure and could hardly explain these offences. In Case 3, the child was hit most likely because of PNESs, which also must be acknowledged under these circumstances. Psychosocial factors are also of relevance, such as being a single parent and suffering from sleep deprivation, and these factors may also have contributed to what happened in these three cases. It is, however, important to examine every case closely to be able to determine the role of seizures, as it is possible but rare with violent acts in relation to seizures.

Based on the results from the focus-group interviews that we have performed, we believe that parents who live under stable psychosocial conditions and who express concern about safety issues concerning their children are at low risk of injuring their children. ${ }^{6}$ On the other hand, children of parents with epilepsy who have suffered a brain injury, have low cognitive function, and who live under difficult situations with little support from their social network could be at risk, and their situation should be acknowledged. Families would benefit from support and guidance, especially when expecting their first child, to prevent accidents from happening. A fear of not being approved as a custodian can prevent parents from discussing the possible risks for their child. It is essential that supportive programs are available for parents with epilepsy, since fear for the safety of one's child increases the psychosocial burden of the condition.

\section{Disclosure}

The authors declare no conflicts of interest in this work. 


\section{References}

1. Marsh L, Krauss GL. Aggression and violence in patients with epilepsy. Epilepsy Behav. 2000;1(3):160-168.

2. Tellez-Zenteno JF, Patten SB, Jetté N, Williams J, Wiebe S. Psychiatric comorbidity in epilepsy: a population-based analysis. Epilepsia. 2007;48(12):2336-2344.

3. Rai D, Kerr MP, McManus S, Jordanova V, Lewis G, Brugha TS. Epilepsy and psychiatric comorbidity: a nationally representative population-based study. Epilepsia. 2012;53(6):1095-1103.

4. Clancy MJ, Clarke MC, Connor DJ, Cannon M, Cotter DR. The prevalence of psychosis in epilepsy; a systematic review and meta-analysis. BMC Psychiatry. 2014;14:75.

5. Pandya NS, Vrbancic M, Ladino LD, Téllez-Zenteno JF. Epilepsy and homicide. Neuropsychiatric Dis Treat. 2013;9:667-673.

6. Gauffin H, Flensner G, Landtblom AM. Living with epilepsy accompanied by cognitive difficulties: young adults' experiences. Epilepsy Behav. 2011;22(4):750-758.

7. Lannon SL. Meeting the needs of children whose parents have epilepsy. J Neurosci Nurs. 1992;24(1):14-18.

8. Thiels C, Steinhausen HC. Psychopathology and family functioning in mothers with epilepsy. Acta Psychiatr Scand. 1994;89(1):29-34.

9. Fazel S, Lichtenstein P, Grann M, Långström N. Risk of violent crime in individuals with epilepsy and traumatic brain injury: a 35-year Swedish population study. PLoS Med. 2011;8(12):e1001150.

10. Gunn J, Bonn J. Criminality and violence in epileptic prisoners. $B r J$ Psychiatry. 1971;118(544):337-343.
11. Kim JM, Chu K, Jung KH, Lee ST, Choi SS, Lee SK. Characteristics of Epilepsy Patients who Committed Violent Crimes: Report from the National Forensic Hospital. J Epilepsy Res. 2011;1(1):13-18.

12. Shih JJ, LeslieMazwi T, Falcao G, Van Gerpen J. Directed aggressive behavior in frontal lobe epilepsy: a video-EEG and ictal spect case study. Neurology. 2009;73(21):1804-1806.

13. Delgado-Escueta AV, Mattson RH, et al. Special report. Special report. The nature of aggression during epileptic seizures. $N$ Engl J Med. 1981;305(12):711-716.

14. Fessler AJ, Treiman DM. Epilepsy and aggression: proceed with caution. Neurology. 2009;73(21):1720-1721.

15. Gerard ME, Spitz MC, Towbin JA, Shantz D. Subacute postictal aggression. Neurology. 1998;50(2):384-388.

16. Treiman DM. Epilepsy and violence: medical and legal issues. Epilepsia. 1986;27 Suppl 2:S77-S104.

17. Reuber M, Mackay RD. Epileptic automatisms in the criminal courts: 13 cases tried in England and Wales between 1975 and 2001. Epilepsia. 2008;49(1):138-145.

18. Kemp AM, Mott AM, Sibert JR. Accidents and child abuse in bathtub submersions. Arch Dis Child. 1994;70(5):435-438.

19. Treiman DM. Violence and the epilepsy defense. Neurologic Clin. 1999;17(2):245-255.

20. Gauffin H, Landtblom AM, Räty L. Self-esteem and sense of coherence in young people with uncomplicated epilepsy: a 5-year follow-up. Epilepsy Behav. 2010;17(4):520-524.
Neuropsychiatric Disease and Treatment

\section{Publish your work in this journal}

Neuropsychiatric Disease and Treatment is an international, peerreviewed journal of clinical therapeutics and pharmacology focusing on concise rapid reporting of clinical or pre-clinical studies on a range of neuropsychiatric and neurological disorders. This journal is indexed on PubMed Central, the 'PsycINFO' database and CAS,

\section{Dovepress}

and is the official journal of The International Neuropsychiatric Association (INA). The manuscript management system is completely online and includes a very quick and fair peer-review system, which is all easy to use. Visit http://www.dovepress.com/testimonials.php to read real quotes from published authors. 